\title{
Rekonstruksi Tari Bedhaya Endhol-endhol di Keraton Kasunanan Surakarta Hadiningrat
}

\author{
Kezia Putri Herawati, Nanik Sri Prihatinia \\ Institut Seni Indonesia (ISI) Surakarta \\ Jalan Ki Hadjar Dewantara No 19 Kentingan Jebres, Surakarta \\ Email: lilikmahfuza@gmail.com
}

\begin{abstract}
The Bedhaya Endhol-endhol dance was created by Paku Buwono X and performed exclusively by the king's daughters. After his death, the dance was no longer performed and its form was no longer known. The goal of this research is to reveal the process of reconstruction of the Bedhaya Endhol-endhol dance, as carried out by Gusti Kanjeng Ratu Wandansari, and to describe the form of the dance. The research method used is a qualitative method with an ethnochoreological approach. The results of the research show the process of reconstruction, including the concept and the process of unearthing the music, or gending, and the dance movements. The arrangement process involved the interpretation of all the different components making up the Bedhaya Endhol-endhol dance, in order to create a new form of bedhaya dance that is childlike (mbocahi). The new form of Endhol-endhol resulted from its reconstruction shows that Gusti Kanjeng Ratu Wandansari has used her authority to restore the dance that had formerly disappeared.
\end{abstract}

Keywords: Bedhaya Endhol-endhol dance, reconstruction, authority, Gusti Kanjeng Ratu Wandansari

\begin{abstract}
ABSTRAK
Tari Bedhaya Endhol-endhol yang khusus ditarikan oleh putri-putri raja diciptakan oleh Raja Paku Buwono X. Sejak beliau wafat tari ini tidak pernah dipentaskan dan bentuknya pun tidak dikenali lagi. Penelitian ini bertujuan mengungkap proses rekonstruksi tari Bedhaya Endhol-endhol dan mendiskripsikan wujudnya yang telah dilakukan oleh Gusti Kanjeng Ratu Wandansari. Metode penelitian yang digunakan adalah metode kualitatif dengan pendekatan etnokoreologi. Hasil penelitian meliputi proses rekonstruksi mencakup konsepnya, proses penggalian meliputi gending dan gerak tarinya. Pada proses penataan dilakukan interpertasi mengenai semua komponen yang membentuk tari Bedhaya Endholendhol untuk mewujudkan tari bedhaya yang mbocahi. Wujud tari Bedhaya Endhol-endhol hasil rekonstruksi menunjukkan bahwa dengan otoritasnya Gusti Kanjeng Ratu Wandansari telah mengembalikan tari yang sempat hilang.
\end{abstract}

Kata kunci: Tari Bedhaya Endhol-endhol, rekonstruksi, otoritas, Gusti Kanjeng Ratu Wandansari 


\section{PENDAHULUAN}

Bedhaya merupakan sebuah tari klasik yang lahir dengan filosofi tinggi diciptakan oleh para raja Mataram. Bedhaya ditarikan oleh sembilan penari perempuan dan disajikan di dalam lingkup kerajaan. Bedhaya yang dimiliki Keraton Kasunanan Surakarta Hadiningrat terdapat 12 bedhaya selain Bedhaya Ketawang, yaitu Bedhaya Pangkur, Sinom, Sukoharjo, Mangunharjo, Gandrung Manis, Dorodasih, Ela-Ela, Endhol-Endhol, Tejanata, Kabor, Miyanggong, dan Bedhaya Tolu. Bedhaya-bedhaya tersebut lahir menurut gending dan sindhenan yang diciptakan pada masa pemerintahan Paku Buwono keII sampai ke-XI. Bentuk tari bedhaya yang mengkiblat pada tari Bedhaya Ketawang yang memiliki makna simbolis kebatinan manusia dengan ajaran-ajaran nilai-nilai kehidupan yang baik untuk kembali kepada-Nya (wawancara GKR. Wandansari tanggal 15 Januari 2015).

Saat ini beberapa tari bedhaya yang masih ditampilkan di Keraton Kasunanan Surakarta, yaitu Bedhaya Sukoharjo, Pangkur, Durodasih, dan Bedhaya Ela-Ela. Sementara Bedhaya-bedhaya yang lain sudah tidak pernah disajikan dalam berbagai acara di Keraton Kasunanan Surakarta Hadiningrat, di antaranya Bedhaya Endholendhol (wawancara Sri Mulyani tanggal 21 November 2014).

Bedhaya Endhol-endhol merupakan bedhaya yang diciptakan oleh Susuhunan Paku Buwono X yang khusus ditarikan oleh putri raja yang masih berusia kanak-kanak atau remaja digunakan untuk menyambut tamu yang datang ke Keraton Surakarta (Marsono, 2000: 108). Tari Bedhaya Endholendhol disusun sekitar tahun 1893-1939 pada saat bertahtanya Paku Buwono $X$ (Darsiti, 1989: 65).

Tari bedhaya biasanya ditarikan oleh perempuan yang bukan keturunan raja atau para abdi dalem bedhaya yang sudah dewasa atau datang bulan, sedangkan penari Bedhaya Endhol-endhol adalah para penari belum pernah mengalami datang bulan (wawancara A. M Hermein tanggal14 April 2016).

Pernikahan putri Paku Buwono X dengan Paku Alam VII turut menjadi bagian sejarah hidupnya Bedhaya Endhol-endhol. Salah satu mahar atau hadiah perkawinan adalah sebuah tari bedhaya, yaitu Bedhaya Tejanata. Ketika permaisuri Paku Alam VII masih hidup beberapa tarian gaya Surakarta ikut diajarkan di antaranya Bedhaya Tejanata, Bedhaya Pangkur, termasuk Bedhaya Endhol-endhol. Terbukti Bedhaya Endhol-endhol pernah dipentaskan di Bangsal Pura Paku Alaman pada tanggal 14 November 1987 (Kusmayati, 1988: 71).

Seiring waktu di Pakualaman tari Bedhaya Endhol-endhol mengalami kemunduran bersama para pelakunya. Sebelumnya pernah dilakukan penataan kembali tahun 1988 sampai 1993 dan terakhir sekitar tahun 1994 ditarikan oleh anak-anak kecil di Bangsal Sewatama Pura Paku Alaman Yogyakarta (wawancara A.M Hermien tanggal 18 April 2016). Adapun di Keraton Surakarta sejak Paku Buwono X wafat sampai sekarang Paku Buwono XIII, Bedhaya Endhol-endhol tidak pernah dipentaskan.

Berdasarkan fenomena tersebut Bedhaya Endhol-endhol telah mengalami kepunahan, sehingga perlu dilakukan penataan kembali atau rekonstruksi. Rekonstruksi tari Bedhaya Endhol-endhol adalah upaya mewujudkan kembali tari Bedhaya Endhol-endhol baru dengan melihat data-data yang tersisa dari masa lampau untuk disajikan pada masa kini. Data tersebut, yaitu gending dan cakepan sindhen yang menjadi data utama untuk merekonstruksi tari Bedhaya Endhol-endhol. Selain gending juga dijumpai data-data tertulis dari para pelaku, keturunan-keturunan raja, dan para abdi dalem yang ada pada masa kepemimpinan Paku Buwono X.

Tari Bedhaya Endhol-endhol memiliki 
keunikan dibandingkan dengan bedhaya lain. Hal itu disebabkan gagasan rekonstruksi tari Bedhaya Endhol-endhol datang dari Gusti Kanjeng Ratu Wandansari dengan otoritas yang dimilikinya. Hal ini bermanfaat untuk dapat memberikan sumbangan konseptual dan material tentang bentuk rekonstruksi tari Bedhaya Endholendhol di Keraton Kasunanan Surakarta Hadiningrat. Selain itu, dapat membantu pelestarian budaya yang dimiliki Keraton Kasunanan Surakarta Hadiningrat dengan menjadikan Bedhaya Endhol-endhol sebagai sajian baru.

\section{METODE}

Tulisan ini merupakan hasil penelitian kualitatif dengan menggunakan metode etnokoreologi yang memokuskan cara pengumpulan data dengan metode interaktif, deskriptif, dan analitik. Kurath menyarankan bahwa metode etnokoreologi pada prosedur penelitian tari terdiri atas 7 tahap, yaitu pertama penelitian lapangan yang berupa pengamatan, mendeskripsikan, dan merekam. Kedua, laboratory study. Tahap ini peneliti melakukan analisis data yang sudah diperoleh. Ketiga, memberi penjelasan tentang gaya tari dan ragamnya. Keempat, menampilkan objek yang diteliti dalam bentuk gambar. Kelima, gambar dipilih menjadi gerak dasar. Keenam, membuat penggabungan sehingga menjadi tarian lengkap. Ketujuh, membuat kesimpulan (Kurath dalam Pramutomo, 2007: 92)

Pengumpulan data berupa pengamatan melalui participant observation mulai bulan Januari 2016 sampai bulan Januari 2017 di Bangsal Smarakata Keraton Kasunanan Surakarta Hadiningrat. Dalam pengumpulan data tersebut diperoleh teknik-teknik dari Gusti Kanjeng Ratu Wandansari dalam melakukan dan mengajarkan hasil rekonstruksinya kepada para penari. Wawancara dilakukan dengan pihak-pihak yang terkait, baik yang terkait langsung, maupun tidak langsung dengan objek kajian. Selain itu, studi pustaka dilakukan guna mendukung kajian penelitian ini.

Analisis data dengan metode interaksi, analisis, dan deskriptif menggunakan data-data lapangan berdasarkan metode dari Kurath. Pada tahap awal adalah mendeskripsikan proses rekonstruksi tari Bedhaya Endhol-endhol di Keraton Kasunanan Surakarta Hadiningrat berdasarkan data yang diperoleh dari lapangan. Tahap kedua laboratory study dengan menggunakan konsep dari Sumandiyo Hadi (2003) untuk menjabarkan bentuk dan hasil rekonstruksi. Tahap berikutnya data-data yang diperoleh dan telah dideskripsikan dicek kembali dengan hasil analisis. Tahap selanjutnya menyusun kesimpulan.

\section{HASIL DAN PEMBAHASAN}

\section{Pelaku Rekonstruksi Tari Bedhaya Endhol- endhol}

Gusti Kanjeng Ratu Wandansari lahir di Surakarta, 1 November 1960 yang merupakan putri ke 25 Ingkang Sinuhun Paku Buwono XII dan putri ke sembilan Raden Ayu Pradapaningrum atau Kanjeng Ratu Ageng. Saat lahir diberi nama G.R.Ay Koes Murtiyah. Nama paringan dalem (artinya pemberian raja) yang digunakan seharihari dalam keraton, yaitu Gusti Kanjeng Ratu Wandansari, dan panggilan akrab para kerabat keraton, yaitu Gusti Moeng. Ia menikah dengan Edy Supriyono yang diberi gelar Dr. Kanjeng Pangeran Eddy S Wirabumi, SH., MM. dan memiliki dua anak, yaitu BRAy. Lung Ayu dan BRAy. Sedhah Mirah.

Keseharian Gusti Kanjeng Ratu Wandansari berada di lingkup kedhaton membuatnya peka terhadap segala sesuatu, baik adat istiadat, budaya, maupun kesenian yang ada, sehingga menjadikannya tidak hanya ahli menari tarian srimpi dan bedhaya, namun juga menabuh gamelan, menyinden, dan tata cara keistanaan dikuasainya 
dengan sangat perigel. Kepekaan terhadap tarian dan gending kemudian membuat Gusti Kanjeng Ratu Wandansari dipercaya oleh ayahanda Paku Buwono XII sebagai penanggung jawab tari-tarian di Keraton Kasunanan Surakarta Hadiningrat. Tanggung jawab Gusti Kanjeng Ratu Wandansari adalah melakukan perawatan terhadap tarian seperti pemadatan tari srimpi maupun bedhaya dan revitalisasi tari seperti tari Bedhaya Pangkur dan Srimpi Dhempel. Selain itu juga gemar menyusun tari untuk kepentingan keraton, seperti tari Bedhaya Sukowati, Bedhaya Retna Tama, Bedhaya Suko Mulya, dan Bedhaya Kirana Ratih.

Rekonstruksi Gusti Kanjeng Ratu Wandansari atas tari Bedhaya Endhol-endhol merupakan wewenang yang dimilikinya yang dapat dikatakan sebagai otoritas. Max Weber menyebut otoritas adalah tindakan dominasi sebagai probabilitas seseorang untuk melakukan suatu perintah (atau semua perintah) yang akan dipatuhi oleh sekelompok orang (Weber dalam George Ritzer, 2014: 140).

Gusti Kanjeng Ratu Wandansari memiliki otoritas legal sebagai Pengageng Wilopo, yaitu Ketua Kantor Sekertaris Keraton, yang berfungsi sebagai pengendali jalannya pemerintahan keraton setelah raja. Menurut Weber, otoritas legal adalah otoritas yang mendapatkan legitimasi rasional berdasarkan pada kepercayaan akan legalitas aturan tertulis dan hak mereka yang diberi otoritas berdasarkan aturan untuk mengeluarkan perintah (Weber dalam George Ritzer, 2014:140).

Gusti Kanjeng Ratu Wandansari juga memiliki otoritas tradisional yang menempel pada dirinya sejak dilahirkan, yaitu berupa legitimasi tradisional didasarkan pada kepercayaan yang telah mapan terhadap kesucian tradisi kuno dan legitimasi mereka yang menjalankan otoritas berdasarkan tradisi tersebut. Pada konteks ini, Gusti Kanjeng Ratu Wandansari memiliki otoritas tradisional dalam bentuk patriarkalis primer, yaitu kepemimpinan yang diperoleh karena warisan.

Gusti Kanjeng Ratu Wandansari memiliki otoritas karismatik pada konteks rekonstruksi tari Bedhaya Endhol-endhol. Menurut Weber, otoritas karismatik adalah otoritas yang mendapatkan legitimasi dari karisma didasarkan pada kesetiaan para pengikutnya terhadap kesucian yang tidak lazim sosok teladan, heroisme, atau kekuatan khusus (misalnya kemampuan menciptakan mukzizat yang dimiliki pemimpin maupun pada tatanan normatif yang diberlakukannya (Weber dalam George Ritzer, 2014: 140). Hal ini berhubungan dengan kemampuan dan kepekaannya, khususnya pada seni tari, dibandingkan dengan saudara-saudara yang lain. Keahliannya tersebut menjadikannya sebagai teladan yang dituakan dan selalu menjadi pelaku untuk tetap hidupnya tari-tarian di Keraton Kasunanan Surakarta Hadiningrat. Demikian keistimewaan yang dimiliki oleh Gusti Kanjeng Ratu Wandansari telah menarik kepercayaan para pendukung rekonstruksi, sehingga semua keputusannya mendapat dukungan sepenuhnya.

\section{Proses Rekonstruksi Tari Bedhaya End- hol-endhol}

\section{a. Ide dan Latar Belakang Rekonstruksi}

Keprihatinan Gusti Kanjeng Ratu Wandansari melihat kondisi saat ini berbeda dengan ketika ia berlatih dahulu. Para penari bedhaya yang merupakan abdi dalem tidak lagi bertempat tinggal di Keputren, karena sekarang sulit mencari penari yang bersedia tinggal di keraton. Jumlah penari yang ada saat ini pun cukup sulit untuk mengharuskan mereka mengingat semua tari, padahal jadwal latihan rutin setiap hari Selasa, Sabtu, dan Minggu. Hal ini dikarenakan latihan tidak maksimal dan materi tari yang dilatihkan selalu yang digunakan untuk pertunjukan atau yang disukai. Mi- 
risnya, penari hanya menghafal bentuk padatnya saja namun tidak mampu menarikan secara utuh tariannya. Hal ini menguatkan alasan perlu diadakannya pelestarian terhadap tarian-tarian keraton, khususnya bedhaya. Oleh karena itu, Gusti Kanjeng Ratu Wandansari mengadakan rekonstruksi tari yang telah mati, revitalisasi tari yang sudah mengalami kemunduran, dan publikasi disertai dokumentasi untuk keperluan dan kepentingan yang akan datang.

Gusti Kanjeng Ratu Wandansari bersama para pemangku adat dan ahli gending Keraton Kasunanan Surakarta Hadiningrat, yaitu Kanjeng Saptono dan para penari kemudian melakukan proses penggalian kembali. Gusti Kanjeng Ratu Wandansari mengatakan bahwa kegiatan rekonstruksi dan revitalisasi dilakukan secara bertahap terhadap semua tari yang ada di Keraton Kasunanan Surakarta Hadiningrat. Hal ini dikarenakan kepentingan tari-tarian di waktu mendatang akan berbeda, baik fungsi dan kegunaannya. Salah satu tari yang direkonstruksi, yaitu tari Bedhaya Endhol-endhol. Rekonstruksi yang dilakukan berupaya mengembalikan tari Bedhaya Endhol-endhol seperti bentuk aslinya. Mengingat tari ini khusus diciptakan untuk anak-anak dengan karakter bocah, maka Gusti Kanjeng Ratu Wandansari menggunakan konsep bocahi ini dalam pijakan merekonstruksi. Konsep yang digunakan sebagai ide penggarapan adalah bedhaya dengan karakter bocah yang memiliki sifat lugu dan sederhana di dalam geraknya.

\section{b. Proses Rekonstruksi}

Rekonstruksi merupakan salah satu usaha merevitalisasi tari. Revitalisasi adalah salah satu upaya pengembangan tari yang dilakukan dengan beberapa kegiatan, yaitu penggalian, rekonstruksi, reinterpretasi, dan reaktualisasi dengan tujuan untuk menghidupkan kembali, melestarikan, mengaktualkan, dan membuat tari lebih berharga (Widyastutiningrum, 2012: 25-26).
Hal ini menempatkan kegiatan rekonstruksi tari Bedhaya Endhol-endhol oleh Gusti Kanjeng Ratu Wandansari pada tujuan untuk melestarikan dan membuat tari itu lebih berharga. Proses rekonstruksi ini menitikberatkan pada penggalian dan reinterpretasi Gusti Kanjeng Ratu Wandasari terhadap tari Bedhaya Endhol-endhol dengan berbekal keahlian dan kepekaannya akan tari-tarian keraton. Pengalaman dan masukan dari kakak-kakaknya juga dimanfaatkan untuk membantu dan memudahkan proses penggalian materi, yaitu penggalian Gending Endhol-Endhol, penggalian gerak tari Bedhaya Endhol-endhol, dan Tempuk Gending.

\section{Interpretasi}

Interpretasi merupakan upaya seseorang dalam menuangkan sesuatu atas pikirannya terhadap sesuatu objek setelah mengolahnya. Interpretasi dilakukan dengan melihat sejarah yang ada mengenai Bedhaya Endhol-endhol, kepekaan, dan keahlian Gusti menguasai tari-tarian di Keraton Kasunanan Surakarta Hadiningrat. Interpretasi ini terdiri atas interpretasi gerak, interpretasi gending, interpretasi pola lantai, dan interpretasi rias dan busana.

\section{a. Interpretasi Gerak}

Interpretasi gerak yang dilakukan oleh Gusti Kanjeng Ratu Wandansari adalah interpretasi yang merujuk pada tari aslinya. Walaupun Gusti Kanjeng Ratu Wandansari sendiri belum pernah menarikan Bedhaya Endhol-endhol, namun pernah dalam ingatannya melihat kakak-kakaknya berlatih tari Bedhaya Endhol-endhol. Gerak yang digunakan memang gerak sederhana untuk mendapat keaslian tari, namun penari yang digunakan oleh Gusti Kanjeng Ratu Wandansari adalah penari dewasa, yaitu para abdi dalem bedhaya. Hal ini dapat dimengerti bahwa rekonstruksi ini tidak membangun persis bentuk asli yang ditarikan oleh anak kecil, karena mencari dan melatih anak kecil sangat sulit, sehing- 
ga untuk mengembalikan bentuk asli yang ditarikan oleh anak kecil juga sekarang sulit dilakukan. Selain keadaan dan situasi tersebut berkaitan pula dengan pola pikir yang Gusti Kanjeng Ratu Wandansari miliki saat ini. Berikut sekaran-sekaran yang memiliki filosofi yang menurut Gusti Kanjeng Ratu Wandansari juga termasuk dalam sekaran yang sederhana.

\section{1) Sekaran Sembahan}

Sembahan pertama, dalam hal ini selayaknya pada tari-tari yang lain yang gerakannya memiliki arti bahwa sebagai umat beragama, dalam melakukan segala sesuatu terlebih dahulu manembah supaya didapat kelancaran. Selain manembah kepada Sang Maha Esa, juga ditujukan kepada leluhur, orang tua, dan raja. Hal tersebut dapat disimpukan bahwa pada awal tari mengajarkan kita untuk selalu manembah. Di sini juga mengajarkan hal kebaikan bahwa sebagai seorang anak manembah kepada Tuhan, orang tua, dan sang raja juga merupakan suatu keharusan. Manembah memang selalu ada dalam tari, ini sebagai wujud penanaman budi pekerti kepada anak-anak.

\section{2) Laras Endhol- Endhol}

Laras Endhol-Endhol merupakan salah satu sekaran yang berbeda dan tidak ada dalam tari bedhaya yang lain. Laras Endhol-Endhol merupakan laras tangguhan yang ada di semua bedhaya. Hanya saja pada tari Bedhaya Endhol-endhol ini disusun dua setengah sekaran yang pada tari Bedhaya Ketawang disusun dengan empat sekaran utuh. Laras Endhol-Endhol diinterpretasi oleh Gusti Kanjeng Ratu Wandansari sebagai gambaran seorang anak yang lugu. Menoleh ke sana ke mari adalah bentuk gerak yang menggambarkan keluguan. Bentuk geraknya dilakukan dengan tangan kiri trap alis dan tangan kanan menthang sampur.

\section{3) Laras Pendhapan Asta}

Laras pendhapan asta merupakan gerakan yang termasuk kategori mudah dibanding dengan laras yang lain. Pada Bedhaya
Endhol-endhol banyak muncul laras yang diinterpretasikan bahwa seorang anak sebaiknya menyaruk atau mengambil dengan jumlah yang banyak, dikumpulkan, disaring, kemudian yang baik disimpan dan yang jelek dibuang. Hal ini digambarkan dari bentuk geraknya. Dari laras ini didapatkan ajaran bahwa seorang anak seharusnya melakukan hal demikian di dalam kehidupan sehari-hari. Selalu menampung segala pengetahuan yang baik dan buruk, kemudian dapat menyerapnya dan menyaring bahwa yang baik dapat ditiru, dipelajari, dan dikembangkan, sedangkan yang buruk sebaiknya dibuang.

\section{4) Laras Pendhapan Sampur}

Laras pendhapan sampur merupakan pola gerak yang juga ada di dalam Bedhaya Ketawang. Sekaran ini dirasa mudah oleh Gusti Kanjeng Ratu Wandansari jika diterapkan kepada anak kecil. Gerakannya hampir sama dengan pola pendhapan asta, hanya saja pada pendhapan sampur tangan kanan menggunakan sampur. Interpretasi Gusti Kanjeng Ratu Wandansari pada sekaran ini bahwa dalam kehidupan sebaiknya selalu andhap asor dan melakukan hal-hal yang baik. Ajaran yang disampaikan kepada anak-anak dalam kehidupan seharusnya andhap asor kepada yang lebih tua dan sesama.

\section{5) Laras Lumaksana Ogek Lambung}

Sekaran laras lumaksana ogek lambung merupakan sebuah susunan gerak dengan peralihan gerak atau gerak transisi melangkah maju. Laras ini memiliki filosofi bahwa dalam kehidupan segala sesuatu perlu dipertimbangkan, lebih-lebih mengambil hal yang baik untuk disimpan dan hal jelek untuk dibuang. Di dalam sekaran ini, diinterpretasikan gerak yang dapat memberikan pesan kepada anak-anak bahwa segala sesuatu yang ditemui dari kehidupan ini perlu ditimbang-timbang, yang baik dan yang buruk, sehingga dapat menentukan kebaikan yang dipilih dan disimpan sebagai bekal untuk kehidupan sehari-hari. 


\section{6) Laras Usap Jangga}

Laras usap jangga yang diinterpretasikan bahwa ngusapi rereget yang artinya menghilangkan kotoran yang melekat pada manusia. Sekaran ini memberikan gambaran bahwa pada manusia muncul banyak kotoran baik yang disengaja ataupun tidak. Kotoran yang muncul dari hati, pikiran, dan tindakan namun ada baiknya jika setelahnya kita membenahi diri menuju kepada kebaikan dan membasuh atau membersihkan semua kotoran yang ada.

\section{7) Laras Lumaksana Ngancap}

Laras ini diinterpretasikan mengenai keluguan seorang anak kecil. Dilihat dari rangkaian geraknya, laras lumaksana ngancap merupakan gerakan yang tolah-tolah dan gedhag-gedheg memperlihatkan perilaku seorang anak dengan keluguan dan tingkah lakunya, namun begitu seorang anak kecil memiliki ketulusan dan kejujuran dalam bertindak.

\section{8) Laras Jeplak-Jeplak Wutuh}

Sekaran jeplak-jeplak wutuh atau biasa dikenal sebagai lembehan wutuh. Jeplak-jeplak wutuh adalah sekaran paling dominan pada tari Bedhaya Endhol-endhol. Sekaran ini merupakan sekaran yang mudah diingat dan sederhana untuk dikuasai oleh anak-anak. Pada sekaran ini Gusti Kanjeng Ratu Wandansari menjelaskan bahwa makna yang terkandung di dalamnya merupakan sebuah ajaran kehidupan manusia, bahwa dalam hidup lebih baik janganlah berbicara terlalu banyak, namun seperlunya dan dengan baik. Seperti diungkap oleh RT. Pamardi Budaya MTH Sri Mulyani bahwa laras jeplak-jeplak memiliki filosofi ajaran kehidupan sebagai ojo seneng cangkeman yang artinya jangan suka berbicara secara tak beraturan. Menyaring perkataan yang akan diucapkan, sehingga apa yang dibicarakan memiliki makna, tidak melukai orang lain, dan menjadi kebaikan bagi kita sendiri dan orang lain.

\section{9) Laras Panahan}

Panahan adalah salah satu gerak yang banyak digunakan pada pola bedhaya. Panahan memiliki arti yang sangat luas, bukan hanya sebagai arti dari sebuah kegiatan memanah, melainkan filosofi bahwa seorang penari bedhaya tidak hanya bertugas sebagai penari. Memanah merupakan gerak yang mengandung arti sebagai ngudi katitisan, lan ngudi keahlian yang bahwasanya seorang penari juga merupakan sorang yang harus memiliki keahlian dan wawasan yang luas serta kegesitan.

\section{0) Laras Pistulan}

Laras pistulan yang ada di dalamnya diinterpretasikan sebagai sebuah pembelajaran, yaitu ajar kaprigelan. Laras pistulan tidak diartikan belajar perang, namun diartikan sebagai anak perlu diajarkan atau dibekali kaprigelan atau ketangkasan dan merupakan bekal yang diajarkan untuk kehidupan mendatang.

\section{1) Laras Engkyek Wutuh}

Laras engkyek wutuh merupakan sebuah susunan gerak yang diinterpretasikan sebagai gerak yang memiliki makna atau ajaran mengenai kebijakan dalam mengambil keputusan. Ditambahkan oleh RT. Pamardi Budaya MTH Sri Mulyani bahwa laras engkyek wutuh merupakan sebuah kebijaksanaan. Di dalamnya mengajarkan untuk menimbang kanan dan kiri baik dan buruknya sebuah keputusan yang bijaksana.

\section{2) Laras Nikelwarti dan Jengkeng Sembahan}

Dalam laras nikelwarti yang dilanjutkan sembahan, merupakan makna dari sebuah ucapan syukur. Manembah ngaturaken panuwun wilujeng, yang artinya menyembah untuk memberikan ucapan syukur karena segala sesuatu yang dilakukan telah terlaksana tanpa suatu halangan.

Dari sekaran-sekaran yang telah menyatu menjadi satu tarian utuh Bedhaya Endhol-endhol, kemudian diinterpretasi oleh Gusti Kanjeng Ratu Wandansari, sehingga 
gerak-gerak dan makna yang terkandung di dalamnya mengenai ajaran-ajaran tentang kebaikan yang seharusnya dilakukan manusia dalam kehidupannya.

\section{a. Interpretasi Gending}

Gusti Kanjeng Ratu Wandansari memiliki interpretasi sendiri mengenai gending pada tari Bedhaya Endhol-endhol. Gending dibuat lebih cepat temponya dibanding gending yang telah ada sebelumnya agar tari tidak begitu nglelet, dikarenakan tarian ini merupakan tarian untuk anak-anak sehingga gending yang semula memiliki tempo lambat kemudian dipercepat. Gending Endhol-Endhol tidak mengalami pengurangan ataupun penambahan. Maka Bedhaya Endhol-endhol yang telah direkonstruksi merupakan bedhaya dalam bentuk wutuh yang tidak mengalami pemadatan. Gusti Kanjeng Ratu Wandansari melakukan interpretasi terhadap seseg dan tidaknya tempo untuk menjadikan keselarasan antara tari dan gending. Gending EndholEndhol memang tidak memiliki keterkaitan terhadap makna dan maksud dari tari Bedhaya Endhol-endhol. Gending hanya berperan sebagai pengiring jalannya tari, sehingga Gusti Kanjeng Ratu Wandansari tidak melakukan pendalaman terhadap cakepan sindhenan secara mendalam. Gusti Kanjeng Ratu Wandansari melakukan agar gending dan tari selaras.

\section{b. Interpretasi Pola Lantai}

Gusti Kanjeng Ratu Wandansari sudah menguasai pola-pola tari bedhaya dan berusaha mengembalikan tari Bedhaya Endhol-endhol sehingga terdapat berbagai perubahan dan cara pandang sebagai berikut berdasarkan filosofi.

Pola lantai montor mabur memiliki ajaran keseimbangan hidup, sehingga Gusti Kanjeng Ratu Wandansari menyelipkan pesan dengan menggunakan pola ini. Pola lantai urut kacang mengajarkan mengenai urut tuo, yang artinya berbaris sesuai dengan umur. Ini mengajarkan menge- nai menghormati yang lebih tua. Di mana seorang yang lebih tua adalah orang yang menjadi panutan untuk orang yang lebih muda. Pada pola urut kacang barisan pertama ditempati oleh batak dan diakhiri oleh boncit. Pola lantai rakit telu-telu memiliki filosofi mengenai babahan hawa sanga atau sembilan lubang yang ada pada manusia. Juga terkait dengan lambang kesatuan saling terkait. Pola lantai blumbangan menggambarkan mengenai suatu ikatan yang tidak terputus. Sebuah kerukunan dan menggambarkan kehidupaan yang dilambangkan dengan blumbangan, sebab dalam blumbangan merupakan tempat di mana air berada, yaitu sumber kehidupan.

\section{c. Interpretasi Rias dan Kostum}

Gusti Kanjeng Ratu Wandansari menginterpretasi berdasarkan foto kakaknya yang sempat menarikan Bedhaya Endholendhol waktu masih kecil. Kostum yang digunakan pada dasarnya seperti pada tari-tarian anak dilingkup keraton, yaitu jarik sabuk wala, kotang, dan bentuk rambut menggunakan sikat sumelat. Walaupun berdasarkan pada kostum yang pernah ada, namun Gusti Kanjeng Ratu Wandansari tidak menggunakan sepenuhnya pada tari yang telah direkonstruksi, yaitu disesuaikan dengan usia penari.

Perubahan terjadi pada jarik yang dulunya menggunakan jarik dengan model sabuk wolo, namun Gusti Kanjeng Ratu Wandansari memilih untuk menggunakan jarik samparan tanpa merusak bentuk sajian tarinya. Dengan pertimbangan bahwa penari merupakan penari yang telah dewasa, sehingga tidak pantas untuk menggunakan jarik bentuk sabuk wolo.

Untuk tata rambut, Bedhaya Endhol-endhol hasil rekonstruksi tetap menggunakan bentuk aslinya, yaitu menggunakan tata rambut sikat sumelat agar tetap mempertahankan bentuknya. Dengan menggunakan tatanan rambut sikat sumelat, kekhasan anak atau kesan mbocahi juga lebih nam- 
pak, untuk perhiasan juga menggunakan adat saben atau yang biasa digunakan tari bedhaya pada umumnya di Keraton Kasunanan Surakarta Hadiningrat.

Interpretasi mengenai tatanan busana yang sedikit berubah tidak bermaksud untuk merubah bentuk dan makna dari tari, namun menerapkan pada fungsinya sekarang, yaitu bedhaya yang ditarikan oleh perempuan dewasa dan dapat dipentaskan di luar lingkup keraton. Jadi dari hasil yang Gusti Kanjeng Ratu Wandansari lakukan selama melakukan proses rekonstruksi dapat disimpulkan bahwa, tari Bedhaya Endholendhol yang disusun adalah bedhaya yang mencoba menghadirkan seperti aslinya. Dari garap gerak dan garap gending semua telah digarap dengan kesederhanaan yang merujuk pada tarian yang mbocahi atau anak-anak. Garap gerak yang sederhana, sedikit jenis sekaran, serta tempo iringan yang lebih cepat membuat tarian memiliki rasa mbocahi. Namun sedikit berbeda dengan pelaku tarinya yang merupakan perempuan dewasa bukan lagi anak-anak kecil seperti pada bentuk aslinya.

\section{Evaluasi}

Gusti Kanjeng Ratu Wandansari melakukan evaluasi guna melihat kembali hasil yang telah dicapai selama melakukan rekonstruksi. Evaluasi dilakukan dengan cara mengulang-ulang secara terusmenerus antara tari dan gending sehingga dirasa benar-benar mantap dan selaras. Evaluasi ini bertujuan untuk benar-benar meneliti secara menyeluruh susunan gerak dan gending. Beberapa kali tari Bedhaya Endhol-endhol hasil rekonstruksi ditarikan untuk mendapatkan hasil yang paten, mapan, dan nyaman untuk ditarikan.

Uji coba pertama dilakukan pada hari Minggu bulan Desember 2016, di hadapan pemangku adat meliputi para gusti dan kanjeng. Pada masa uji coba Gusti Kanjeng Ratu Wandansari mendapat masukan dan arahan dari kakaknya, yaitu Gusti Kan- jeng Ratu Galuh Kencana, kemudian para penari mendapat pembenahan gerak dari para gusti agar dapat mencapai gerak yang maksimal. Beberapa gerak dibenahi dengan tujuan mendapatkan kesempurnaan hasil.

Latihan kembali sebagai bentuk koreksi yang dilakukan tiga minggu sebelum dilakukan pendokumentasian, yaitu pada tanggal 8, 15, dan 22 Januari 2017. Pada tahap ini, Gusti Kanjeng Ratu Wandasari konsentrasinya dicurahkan pada sembilan penari yang khusus memperagakan pada pendokumentasian. Koreksi yang didapat diterapkan dan dilakukan terus-menerus dengan gending. Hasil rekonstruksi didokumentasikan tanggal 23 Januari 2017 di Bangsal Smarakata Keraton Kasunanan Surakarta Hadiningrat pukul 19.30 WIB. Dari hasil pendokumentasian dapat disimpulkan bahwa tari Bedhaya Endhol-endhol hasil rekonstruksi oleh Gusti Kanjeng Ratu Wandansari mewutuhkan atau menghasilkan tari secara menyeluruh dengan durasi tari 41 menit.

\section{Struktur dan Elemen Tari Bedhaya Endhol- endhol}

Struktur tari Bedhaya Endhol-endhol hasil rekonstruksi terdiri atas tiga bagian, yaitu maju beksan, beksan, dan mundur beksan. maju beksan adalah bagian pertama pada setiap tari khususnya tari Jawa. Pada tari Bedhaya Endhol-endhol, maju beksan dilakukan dengan berjalan dari samping kanan pendhapa menuju tempat pertunjukan dengan pola urut kacang yang diawali oleh penari endhel ajeg, batak, apit mlaku ngarep, apit mlaku mburi, gulu, apit meneng, endhel weton, dada, dan diakhiri oleh boncit. Lumaksana kapang-kapang diiringi dengan pathetan laras pelog pathet barang. Gerak yang dilakukan adalah berjalan kapang-kapang dengan diiringi pathetan dan sulukan. Semua penari berjalan berurutan membentuk pola montor mabur menghadap ke Utara. Setelah semua penari menempati 
tempat masing-masing dan berdiam diri, kemudian pengeprak memberi tanda untuk bersamaan para penari menghadap ke Timur arah para penonton. Pengeprak memberikan tanda kembali kemudian penari melakukan debeg gejug dan proses duduk bersila atau trapsilantaya. Setelah trapsilantaya maka pathetan juga akan berakhir dan dimulailah buka gending Endhol-endhol.

Beksan adalah inti dari sebuah sajian tari. Pada beksan tari Bedhaya Endhol-endhol terbagi menjadi dua bagian. Bagian pertama diiringi dengan gending Endholendhol dilanjutkan Ladrang Manis sebanyak 16 gongan. Bagian pertama terdiri dari beberapa gerak, yaitu sembahan berdiri atau gerak penyambung, laras Endhol-endhol, pendhapan asta, pendhapan sampur, lumaksana ogek lambung, lembehan atau pendhapan asta, laras Endhol-endhol, sekaran ngancap, srisig, pendhapan asta separo, pendapan sampur separo, srisig tawing, laras usap jangga, lumaksana ngancap, srisig sampur, jeplak-jeplak wutuh, engkyek kanan kiri wutuh, dan diakhiri dengan laras nikelwarti atau jengkeng. Bagian kedua diiringi dengan gending Ketawang Kaum dhawuk dengan jumlah gongan 29 kali. Urutan gerak pada bagian kedua diawali dengan berdiri, laras jeplakjeplak separo, jeplak-jeplak wutuh tiga kali, jeplak-jeplak separo, laras panahan, dan jengkeng kembali. Hanya batak dan endel ajeg yang kemudian berdiri melakukan gerakan perangan yang terdiri dari hoyogan, lembehan wutuh sebanyak tiga kali, laras mangklung, lembehan wutuh, srisig sampir sampur menuju pola lantai blumbangan. Pada bagian pola blumbangan gerak yang dilakukan secara berurutan adalah laras pistulan wutuh, srisig sampir menuju pada pola rakit telu-telu, laras jeplak-jeplak wutuh kemudian kembali jengkeng trapsilantaya.

Mundur beksan, yaitu ke luarnya penari dari tempat pertunjukan tari semenjak posisi trapsilantaya kemudian berdiri dan kembali pulang menuju tempat persiapan melewati samping kanan pendhapa dengan jejer urut kacang kembali. Pada tari Bedhaya Endhol-endhol hasil rekonstruksi oleh Gusti Kanjeng Ratu Wandansari, mundur beksan menggunakan pola mundur beksan kapang-kapang dan diiringi dengan pathetan. Seperti halnya pada maju beksan, penari pada mundur beksan melakukan lumaksana kapang-kapang dari pendhapa pementasan menuju samping kanan pendhapa. Berbeda dengan saat maju beksan, pada saat mundur beksan urut-urutan penari diawali oleh endel ajeg, batak, endel weton, gulu, boncit, kemudian apit ngarep, dada, apit mlaku mburi, dan apit meneng.

\section{Elemen-elemen Tari Bedhaya Endhol-endhol}

Otoritas Gusti Kanjeng Ratu Wandansari telah mewujudkan tari Bedhaya Endholendhol menjadi tarian utuh yang dapat dideskripsikan dari aspek-aspek sebagai berikut : (1) Deskripsi Tari, (2) Gerak Tari, (3) Pola Lantai, (4) Karawitan Tari, (5) Jumlah dan Jenis Kelamin, dan (6) Rias dan Busana,

\section{(1) Deskripsi Tari}

Tari Bedhaya Endhol-endhol hasil rekonstruksi oleh Gusti Kanjeng Ratu Wandansari merupakan tari kelompok putri yang terdiri dari sembilan penari. Penari tersebut adalah penari bedhaya yang telah dewasa bukan penari anak-anak seperti tari Bedhaya Endhol-endhol sebelumnya. Sembilan penari memiliki filosofi mengenai babahan hawa sanga atau sembilan lubang manusia. Struktur gerak dan elemen tari Bedhaya Endhol-endhol mengkiblat pada tari Bedhaya Ketawang. Pola-pola simetris digunakan, hanya saja yang membedakannya terdapat pola lantai blumbangan yang tidak ada pada tari Bedhaya Ketawang. Reinterpretasi pola-pola gerak yang digunakan pun sederhana dengan mengulang-ulang gerak jeplak-jeplak wutuh, pendhapan sampur, dan pendhapan asta. Hal ini dikarenakan Bedhaya Endhol-endhol adalah bedhaya 
yang diciptakan oleh Ingkang Sinuhun Paku Buwono X khusus untuk para puti raja yang masih kanak-kanak atau remaja. Struktur musik tari menggunakan gending Endhol-Endhol dilanjutkan dengan $\mathrm{La}$ drang Manis dan kemudian Ketawang Kaum dhawuk. Namun dari cakepan sindhen dengan tari tidak memiliki tema yang sama, sehingga musik tarinya hanya berfungsi sebagai pembentuk irama atau dinamika. Rias busana menggunakan kotang warna ungu, kain cinden ijo pupus dengan tatanan rambut sikat sumelat dilengkapi perhiasan. Berbeda dengan aslinya yang menggunakan kotang merah muda dan kain yang dibentuk sabuk wolo. Hal ini berkaitan Bedhaya Endhol-endhol yang sekarang ditarikan oleh wanita dewasa yang dapat ditarikan di luar tembok keraton.

\section{(2) Gerak Tari}

Gerak tari adalah komposisi gerak yang mengalami penggarapan. Pada tari Bedhaya Endhol-endhol hasil rekonstruksi digunakan gerak-gerak yang ada sebelumnya. Gerak-gerak yang tersusun telah mengalami stilisasi dan distorsi. Pada dasarnya gerak yang digunakan merupakan gerak tari putri khas gaya Keraton Kasunanan Surakarta Hadiningrat, yaitu gerak-gerak yang lembut, lemah gemulai, dan telah melalui stilisasi. Variasi gerak pada tari Bedhaya Endhol-endhol terdiri atas motif gerak, gerak pengulangan, dan gerak transisi.

\section{a. Motif Gerak}

Motif gerak yang tersusun pada tari Bedhaya Endhol-endhol adalah Sembahan, Laras Endhol-endhol, Laras Pendhapan Asta, Laras Pendhapan Sampur, Laras Lumaksana Ogek Lambung, Srisig Sampir Sampur, Laras Usap Jangga, Srisig Tawing, Laras Lumaksana Ngancap, Laras Jeplak-Jeplak Wutuh, Laras Panahan, Perangan, Laras Pistulan, Laras Engkyek Wutuh, Nikelwarti, dan Jengkeng.

\section{b. Gerak Pengulangan}

Gerak-gerak yang dominan muncul pada Bedhaya Endhol-endhol hasil rekon- struksi oleh Gusti Kanjeng Ratu Wandansari terdapat tiga pola, yaitu laras pendhapan asta, laras pendhapan sampur, dan laras jeplak-jeplak wutuh. Katiga pola sekaran ini mendominasi susunan gerak tari Bedhaya Endhol-endhol. Pada bagian pertama pendhapan asta dan pendhapan sampur dilakukan dua kali, yaitu pada pola lantai montor mabur dan urut kacang. Pada bagian kedua muncul pada pola lantai rakit telu-telu, montor mabur, perangan, dan rakit telu-telu terakhir. Sementara sekaran jeplak-jeplak wutuh lebih sering muncul, yaitu pada bagian pertama pada pola rakit telu-telu dan pada bagian kedua pada pola rakit telu-telu terakhir menuju nikelwarti.

\section{c. Gerak Transisi}

Gerak transisi merupakan gerak yang dilakukan untuk berpindah tempat. Susunan gerak pada rekonstruksi tari Bedhaya Endhol-endhol terdapat tujuh gerak transisi, yaitu Srisig Sampir Sampur, Srisig Tawing, Srisig Sampur Kiri, Ngetoni Lumaksana Ogek Lambung, Lumaksana Ngancap, dan Kengser.

\section{(3) Pola Lantai}

Pola lantai atau yang disebut dengan desain lantai dan desain ruang adalah garis yang dibentuk dari garis-garis yang tercipta oleh penari. Tari Bedhaya Endhol-endhol ditarikan oleh sembilan penari yang digunakan untuk menyusun pola-pola lantai, yaitu gawang montor mabur, montor mabur berhadapan, montor mabur adu kiri, montor mabur perangan, urut kacang, rakit telu-telu, dan blumbangan.

\section{a. Montor Mabur}

Montor mabur merupakan pola lantai pertama kali yang ada dalam Bedhaya Endhol-endhol. Pola montor mabur menyerupai pesawat terbang. Pola ini memiliki filosofi mengenai keseimbangan di dalam kehidupan. Pola montor mabur digunakan pada gerak sembahan pertama, gerak laras Endhol-endhol, perangan, laras lumaksana ogek lambung, laras usap jangga, dan laras lumaksana ngancap. Pada bagian kedua pola 
lantai montor mabur digunakan pada laras jeplak-jeplak wutuh. Selain itu bagian perangan menggunakan pola montor mabur adu kiri di mana batak dan endel ajeg berdiri dan penari lainnya melakukan gerak dengan posisi jengkeng adu kiri antara tiga penari dan enam penari lainnya.

\section{b. Montor mabur Berhadapan}

Montor mabur berhadapan masih sama dengan pola montor mabur. Pola ini menggambarkan keseimbangan kehidupan yang digambarkan dengan dua tungkai dan dua lengan. Montor mabur berhadapan hampir sama dengan hewan kalajengking. Montor mabur berhadapan ini terjadi pada pola pertama setelah kedua apit ngarep dan mburi melakukan proses ngetoni saat laras Endhol-endhol. Montor mabur berhadapan digunakan pada bagian pertama saat laras pendhapan asta, laras pendhapan sampur, laras lumaksana ogek lambung, laras lumaksana ngancap, dan laras usap jangga.

\section{c. Urut kacang}

Urut kacang adalah pola di mana penari berbaris menjadi satu secara horizontal dipimpin oleh batak, diikuti oleh gulu, dan diakhiri oleh boncit. Pola lantai urut kacang terjadi sekali pada bagian pertama dengan sekaran pendhapan asta separo dan pendhapan sampur separo disambung srisig tawing.

\section{d. Montor mabur Ngetoni}

Pola montor mabur ngetoni merupakan pola yang terjadi dengan adanya proses ngetoni. Pola ini digunakan setelah pola lantai urut kacang dengan gerak transisi srisig tawing yang kemudian dilanjut dengan laras usap jangga.

\section{e. Rakit telu-telu}

Pola rakit telu-telu ada pada bagian awal, pertengahan, dan akhir bagian pertama dan bagian kedua. Pada pola ini selalu terjadi tiga bentuk, yaitu pola rakit telu posisi berdiri, pola rakit telu posisi jengkeng, dan trapsilantoyo. Filosofi rakit telu-telu adalah ajaran untuk mengawali dan mengakhiri segala sesuatu dengan doa dan ucapan syukur.

\section{f. Blumbangan}

Blumbangan adalah bentuk atau pola yang dalam bahasa Indonesia adalah $l u$ bangan. Blumbangan dilakukan pada bagian kedua saat sekaran pistulan. Filosofi yang digambarkan pola ini adalah keselarasan, kerukunan, dan kehidupan, sebab di dalam blumbangan menggambarkan adanya air sumber kehidupan manusia. Untuk sekarannya tidak diartikan mengenai pistulan yang sesungguhnya, namun memiliki arti mengenai memerangi nafsu jahat yang timbul dari pikiran manusia.

\section{g. Gawang Perangan}

Gawang perangan juga menggunakan pola montor mabur dengan posisi penari adu kiri. Posisi batak dan endel ajeg berdiri dengan melakukan perangan dengan sekaran jeplak-jeplak wutuh dan usap jangga. Sedangkan ketujuh penari melakukan gerak yang sama dengan posisi jengkeng. Kedua penari melakukan gerak dengan transisi untuk bertukar tempat satu putaran dan kembali ke tempat masing-masing.

\section{(4) Karawitan Tari}

Gending tari Bedhaya Endhol-endhol terdiri dari gending Endhol-endhol, Ladrang Manis, dan Ketawang Kaum dhawuk laras pelog pathet barang. Gending Bedhaya Endhol-endhol merupakan gending yang hanya berfungsi sebagai iringan. Gending tari yang digunakan dalam pertunjukan tari Bedhaya Endhol-endhol disajikan pada perangkat Gamelan Ageng laras slendro dan pelog. Gending tari Bedhaya Endhol-endhol rangkaian dari gending Endhol-endhol, $\mathrm{La}$ drang Manis, dan Ketawang Kaum Dawuk laras pelog pathet barang. Gending tari Bedhaya Endhol-endhol vokal sangat mendominasi untuk menyusun suasana, sama seperti musik dalam tari Sanghyang Dedari yang terdiri dari 7 bait (Nanik Sri Prihatini, 2008: 45). Dalam sajian tari tersebut vokal mendominasi sebagai unsur pembentuk suasana.

(5) Jumlah dan Jenis Kelamin

Jumlah dan jenis kelamin penari meru- 
pakan sebuah realisasi konsep dan interpretasi. Jumlah penari tari Bedhaya Endhol-endhol sebanyak sembilan orang perempuan. Jumlah tersebut memiliki konseptual babahan hawa sanga atau disebut sembilan lubang pada manusia yang menyebabkan hawa nafsu baik maupun buruk.

\section{(6) Rias dan Busana}

Rias yang digunakan pada tari Bedhaya Endhol-endhol adalah rias corrective, yaitu merias dengan tujuan menambah kecantikan dengan cara memperindah bagian yang perlu ditonjolkan dengan alat kecantikan. Tata rambut menggunakan tata rambut yang diikat menjadi satu dan dirapikan menggunakan rajut, kemudian dimasukan ke dalam kantong gelung yang diberi pita beserta bros, serta dibubuhkan beberapa kostum dan perhiasan kepala yang berupa sunduk mentul, bulu, dan sunduk jungkat. Dahulu tata rambut seperti ini tidak menggunakan kantong gelung namun rambut dikepang kemudian ditekuk yang dinamakan sikat sumelat.

Dua versi memperlihatkan kostum Bedhaya Endhol-Endol terdahulu, pertama menggunakan bentuk kostum sabuk wolo, dan yang kedua menggunakan kotang berwarna merah muda atau jambon. Namun saat ini kostum yang digunakan adalah kostum bedhaya sewajarnya yang ada di keraton dan yang dapat digunakan untuk pertunjukan di luar tembok keraton. Hal ini berhubungan dengan bedhaya yang telah direkonstruksi nantinya dapat dipertunjukan di luar keraton dengan tujuan untuk mengadakan promosi dan revitalisasi. Kostum yang digunakan pada Bedhaya Endhol-endhol hasil rekonstruksi adalah jarik samparan cinden ijo pupus, kotang ungu, sampur pink atau jambon, slepe, totog, jamang, sumping, sunduk mentul, bulu, kantong gelung pita bros, sunduk jungkat, gelang, dan cincin.

Jarik samparan cinden merupakan jarik yang biasa digunakan pada tari bedhaya yang ada di dalam Keraton Kasunanan Surakarta Hadiningarat. Dari pemilihan warna Gusti Kanjeng Ratu Wandansari menggunakan warna hijau adalah untuk menarik ke dalam konsep konteks bocahi. Bahwa warna hijau pupus adalah warna dari daun yang masih muda atau kuncup, begitu pun kaitannya dengan tari Bedhaya Endhol-endhol yang merupakan tarian anak-anak. Kotang warna ungu berkaitan dengan pemikiran dan interpretasi bahwa Bedhaya Endhol-endhol yang sekarang merupakan bedhaya yang dapat ditarikan di luar lingkup kraton. Sampur merupakan salah satu komponen dalam kostum tari yang terpenting. Sampur yang dipilih pada pertunjukan hasil rekonstruksi tari Bedhaya Endhol-endhol adalah warna jambon atau merah muda. Pemilihan warna merupakan takaran estetika yang berhubungan dengan warna kotang yang digunakan. Warna jambon identik dengan warna perempuan yang halus dan lembut. Sementara itu seperangkat perhiasan yang digunakan dalam tari Bedhaya Endhol-endhol hasil rekonstruksi sebagian besar tetap mempertahankan bentuk aslinya, yaitu anak-anak identik dengan perhiasan dan tatanan rambut yang sederhana. Tatanan yang sederhana dan perhiasan yang tidak banyak yaitu pada kepala menggunakan kantung gelung, sunduk mentul, bulu, serta bros kecil pada kantung gelung yang dibubuhi pita. Kemudian perhiasanya berupa sunduk jungkat, anting atau giwang, gelang, kalung, dan cincin.

\section{SIMPULAN}

Berdasarkan hasil pembahasan dapat disimpulkan bahwa untuk melestarikan tari-tarian di Keraton Kasunanan Surakarta Hadiningrat maka dilakukan rekonstruks beradasarkan otoritas yang dimiliki Gusti Kanjeng Ratu Wandansari. Ia memiliki tiga otoritas yang menguatkannya sebagai pelaku rekonstruksi, yakni otoritas legal bahwa ia bertindak sebagai pengageng Wilo- 
po, otoritas tradisional bahwa ia merupakan keturunan dari seorang raja, dan otoritas karismatik bahwa ia memiliki karisma (kepekaan) pada bidang tari dibandingkan dengan saudara-saudara yang lain. Ketiga otoritas tersebut memberi kekuasaan penuh kepada Gusti Kanjeng Ratu Wandansari dalam rekonstruksi tari Bedhaya Endhol-endhol.

Bedhaya Endhol-endhol adalah tari bedhaya yang diciptakan oleh Paku Buwono $\mathrm{X}$ khusus untuk putri-putrinya yang masih kanak-kanak dengan gerak-gerak sederhana dan lebih menghadirkan karakter bocah dengan sifat lugunya. Hal tersebut sebagai pijakan Gusti Kanjeng Ratu Wandansari untuk menginterpretasikan bentuk Bedhaya Endhol-endhol di masa lalu ke masa sekarang.

Proses rekonstruksi selama 11 bulan terdiri atas penggalian gending, penggalian gerak, dan tempuk gending menghasilkan tari Bedhaya Endhol-endhol baru berdurasi 41 menit dengan sekaran-sekaran sederhana, tempo sedikit seseg, dan kostum disesuaikan dengan penari yang digunakan oleh Gusti Kanjeng Ratu Wandansari, yaitu penari dewasa. Sekaran sederhana tersebut di antaranya laras Endhol-endhol, pendhapan asta, pendhapan sampur, lumaksana ogek lambung, laras usap jangga, lumaksana ngancap, lembehan jeplak-jeplak wutuh, pistulan, panahan, dan engkyek wutuh. Di antara sekaran tersebut lembehan jeplak-jeplak wutuh, pendhapan asta, dan pendhapan sampur merupakan sekaran yang mendominasi tari Bedhaya Endhol-endhol hasil rekonstruksi oleh Gusti Kanjeng Ratu Wandansari.
Hasil rekonstruksi tari Bedhaya Endhol-endhol menunjukkan bahwa Gusti Kanjeng Ratu Wandansari belum dapat mewujudkan konsep tari Bedhaya Endholendhol yang menitikberatkan pada karakter bocah. Hal ini dikarena sembilan penari perempuan dewasa dalam tari Bedhaya Endhol-endhol baru belum dapat memerankan karakter anak dengan maksimal, sehingga rasa mbocahi tidak tampak dan tidak mampu mempengaruhi suasana pertunjukan. Meskipun demikian, Gusti Kanjeng Ratu Wandansari telah berjasa mengembalikan kembali tari Bedhaya Endhol-endhol yang sempat ditinggalkan.

\section{Daftar Pustaka}

Hermien, A. M. K. (1988). Bedhaya di Pura Paku Alaman Pembentukan dan Perkembanganya 1909-1987, (Tesis). Fakultas Pascasajana. Universitas Gadjah Mada, Yogyakarta.

Marsono, W. (2000). Ensiklopedi Budaya Jawa. Surakarta: Gramedia.

Prihatini, N. S. (2005)."Sanghyang Dedari: Kajian Teks dan Konteks". Panggung, 18 (1), 41-53.

Pramutomo, RM. (2007). Etnokoreologi Nusantara Batasan Kajian Sistematika dan Aplikasi Keilmuannya. Surakarta: ISI Press.

Ritzer, G. dan Douglas J. G. (2014). Teori Sosiologi. Yogyakarta: Kreasi Wacana.

Soeratman, D. (1989). Kehidupan Dunia Keraton Surakarta 1830-1939. Yogyakarta: Tamansiswa.

Widyastiningrum, S. R. (2012). Revitalisasi Tari Gaya Surakarta. Surakarta: ISI Press. 